\title{
Concordance between estimates of acute malnutrition measured by weight-for- height and by mid-upper arm circumference after age adjustment: population-representative surveys from humanitarian settings
}

\author{
Eva Leidman * ${ }^{*}$, Alexia Couture, Erin Hulland and Oleg Bilukha
}

\begin{abstract}
Background: Mid-upper arm circumference (MUAC) and weight-for-height (WHZ) are commonly used indicators to identify acute malnutrition. However, MUAC and WHZ diagnose different children, and produce prevalence estimates that are meaningfully different. Previous research in Somalia has suggested improved concordance using MUAC-for-age (MUACZ) rather than MUAC. We further evaluate the relationship between MUACZ, MUAC, and WHZ using surveys conducted globally.

Methods: We analyzed 882 population representative surveys from 41 countries. Children ages 6-59 months were classified as acutely malnourished using three independent criteria: WHZ $<-2$ (WHZ2), MUAC $<125$ mm (MUAC125), MUACZ < - 2 (MUACZ2). Population prevalence using each of the three criteria are presented by country and region. Correlations of survey prevalence for each indicator pair were assessed. Multivariable regression models of MUACZ and MUAC125 adjusted for WHZ2, stunting prevalence, age, and sex. To evaluate individual level diagnostic concordance, we compared the proportion of children identified by each of the three criteria.

Results: Median prevalence of acute malnutrition overall was highest for MUACZ2 (14.0\%) followed by WHZ2 (10.6\%), and lowest for MUAC125 (7.3\%). The absolute difference in prevalence between MUACZ2 and WHZ2 was smaller than the difference between MUAC125 and WHZ2 for 51.3\% of surveys. The correlations of WHZ2 with both MUACZ2 as well as with MUAC125 were weak, positive associations (Pearson's $r=0.5757$ and 0.4943 , respectively), but MUAC125 and MUACZ2 had a strong, linear relationship (Pearson's $r=0.9265$ ). The adjusted regression model for MUACZ2 had greater fit $\left(R^{2}=0.50\right)$ relative to the adjusted model for MUAC125 $\left(R^{2}=0.43\right)$. The proportion of children identified by both MUAC125 and WHZ2 was 25.5\%, smaller than the proportion identified by both MUACZ2 and WHZ2 (30.6\%).

\footnotetext{
* Correspondence: eleidman@cdc.gov

Emergency Response and Recovery Branch, Division of Global Health

Protection, Center for Global Health, Centers for Disease Control, 1600 Clifton

Road, Atlanta, GA 30329, USA
}

C The Author(s). 2019 Open Access This article is distributed under the terms of the Creative Commons Attribution 4.0 International License (http://creativecommons.org/licenses/by/4.0/), which permits unrestricted use, distribution, and reproduction in any medium, provided you give appropriate credit to the original author(s) and the source, provide a link to the Creative Commons license, and indicate if changes were made. The Creative Commons Public Domain Dedication waiver (http://creativecommons.org/publicdomain/zero/1.0/) applies to the data made available in this article, unless otherwise stated. 
(Continued from previous page)

Conclusions: MUACZ identified more children as malnourished than MUAC, resulting in a higher prevalence of acute malnutrition in nearly all settings. Prevalence by MUACZ was not consistently more similar to WHZ than that estimated by MUAC, and correlations with WHZ were only slightly improved relative to MUAC. Consequently, programmatic use of MUACZ cannot be justified based on improved concordance with WHZ. Further research on morbidity and mortality of children with low MUACZ only are needed before recommending MUACZ for wider use.

Keywords: Wasting, Survey, Nutrition, Humanitarian

\section{Background}

Presence of acute malnutrition in children is ascertained through anthropometric measurement. Two independent anthropometric indicators have been endorsed by the Standing Committee on Nutrition (SCN) and are widely used in determining admission into selective nutrition treatment programs as well as assessing population prevalence -weight-for-height Z-score (WHZ) and mid-upper arm circumference (MUAC) [1-3].

While these indicators intend to measure the same condition of acute malnutrition, numerous studies have found that the children identified for admission to treatment programs by the two indicators are not the same. A 2009 report by the World Health Organization (WHO) [3] noted that of all children identified as acutely malnourished by either indicator, only about $40 \%$ of children were identified by both. This finding of poor child level diagnostic concordance of these indicators has since been independently replicated using different samples of children. Based on analysis of data from 14,409 children in 4 countries, Roberfroid et al. [4] found that only $28.5 \%$ of children defined as acutely malnourished were diagnosed by both low MUAC and low WHZ. Similarly, Grellety et al. [5] reviewed data from 1,832 surveys containing measurements of 1,384,068 children from 47 countries, and found only $28.2 \%$ of children defined as acutely malnourished were diagnosed by both MUAC and WHZ. The proportion of children identified by both indicators in their study varied by country, but was consistently less than $40 \%$.

Subsequent research has demonstrated that these diagnostic differences translated into meaningful variations in the population-prevalence of acute malnutrition determined by the two-indicators; a contrast to the initial intention of researchers to derive MUAC prevalence cut-offs for programmatic action and severity classification that corresponded with those produced by $\mathrm{WHZ}<-2$ [6]. Based on analysis of 733 surveys from 41 countries, Bilukha and Leidman [7] found poor correlation between population prevalences of acute malnutrition by WHZ and by MUAC, even after adjusting for prevalence of stunting, sex and age ratios $\left(R^{2}=0.46\right)$. The research suggested that prevalence of WHZ was higher than MUAC in most surveys, but the reverse could be identified in select populations.

Researchers have hypothesized that MUAC-for-age (MUACZ) may have more diagnostic consistency with WHZ than MUAC due to the fact that MUACZ is adjusted by age and sex. As such, the calculation of the MUACZ indicator is similar to WHZ, both of which compare a child's anthropometric measurements to an international reference population, whereas a single threshold is used for MUAC irrespective of age (125 $\mathrm{mm}$ ) to classify acute malnutrition in children aged 659 months. Preliminary evidence from Somalia supports this hypothesis. Custodio et al. [8] found that prevalence of low MUACZ (15.8\%) and WHZ (16.1\%) from a pooled sample of 17 surveys conducted in Somalia between 2007 and 2016 were very similar, whereas prevalence of low MUAC (7.8\%) was much lower. Analysis of children in the sample found that the proportion of acutely malnourished children identified by both WHZ and MUACZ (28.3\%) was higher than the proportion of children identified by both WHZ and MUAC (18.1\%).

Findings of improved diagnostic similarity of MUACZ and WHZ, relative to MUAC, may have broad practical implications. First, current global protocols for therapeutic feeding centers that recommend measuring midupper arm circumference nearly all include admission on low MUAC not low MUACZ. Second, measurement of MUAC using color-banded strips is widely used in humanitarian settings in large part given its simplicity, demonstrated to be feasible for low-literacy community members with limited training [9]. Screening children with MUACZ is more complex as it additionally requires both accurately ascertaining age and using a reference table to identify children with low MUACZ. Measuring age can be difficult and time-consuming in contexts with poor vital registration [9]. Use of the reference table requires both literacy and training [10]. Finally, as MUACZ is age standardized, use of the indicator would likely shift the mean age of children at admission. Absolute MUAC and age are correlated in the reference population; median MUAC values in the WHO standard population increase by approximately $17 \mathrm{~mm}$ between 12 and 59 months $[8,11]$. Research by Hossain et al. [12], 
found that among Bangladeshi children a MUAC cutoff of $15 \mathrm{~mm}$ higher for children 37-60 months compared to children 6-24 months (140 v. $125 \mathrm{~mm}$ ) had similar sensitivity and specificity as WHZ.

The aim of our study is therefore to further investigate the relationship between both indicator pairs (WHZ and MUAC v. WHZ and MUACZ) to assess differences in population prevalence and individual child diagnosis when using MUACZ vs. MUAC. Building on the work of Custodio et al. [8], using a larger and more diverse set of population representative surveys including children from countries globally, we aim to evaluate whether their findings hold for all regions. Given that MUACZ, but not MUAC, is an age standardized indicator, we also explore whether the relationship between MUACZ, MUAC and WHZ is consistent for all age groups. Further, to understand the practical implications of using MUACZ, we evaluate the diagnostic concordance of MUAC and MUACZ.

\section{Methods}

Data reviewed for analysis were single stratum, crosssectional, population representative surveys (subsequently referred to as "small-scale surveys") provided by the United Nations High Commissioner for Refugees (UNHCR) and by Action Contre le Faim (ACF). Surveys were reviewed if they were conducted between 2013 and 2016 (UNHCR) and 2001-2017 (ACF) and measured age, sex, weight, height and MUAC in children aged 659 months. Survey datasets were examined for duplication prior to inclusion in the study.

Surveys with sample size smaller than 196 persons and cluster surveys with fewer than 25 clusters were excluded from all analyses as they did not meet minimum standards for small scale surveys [5, 13]. Surveys missing MUAC, height, weight, or cluster variable (if two-stage study design) for more than $20 \%$ of sampled children were also excluded from analysis. Additionally, surveys with standard deviations (SD) of mid-upper arm circumference (MUAC) greater than $160 \mathrm{~mm}$ or SD of the underlying $\mathrm{z}$-score distribution greater than 1.3 for weight-for-height (WHZ) or MUAC-for-age (MUACZ) were excluded given concerns regarding quality of anthropometric measurements $[14,15]$. Finally, a survey with an implausible ratio of males to females (>125:1) was also excluded. Within surveys retained for analysis, children were excluded if age was missing or out of range (6.0-59.99 months) or if the child record was an exact duplicate of another for all variables including household and cluster number within the dataset.

Survey countries were categorized into seven regions: Latin America and the Caribbean; Eastern and Southern Africa; Democratic Republic of Congo (DRC); West and Central Africa; Southeast Asia and Pacific; Sudan; and
Middle East and North Africa [16]. Sudan and DRC were kept as their own regions due to large number of surveys from each country.

Weight-for-height (WHZ), MUAC-for-age (MUACZ), and Height-for-age (HAZ) z-scores were calculated for all children using the WHO SAS macro, which applies the WHO 2006 growth standards [17]. Children with missing data for sex, weight, height or MUAC were excluded by indicator, such that a child with missing weight would be excluded from WHZ but not MUAC or MUACZ calculations. For each survey, prevalence of acute malnutrition was calculated independently for three indicators. Prevalence of acute malnutrition by WHZ (herein referred to as "WHZ2") was defined as $\mathrm{WHZ}<-2$. Prevalence of acute malnutrition by MUACZ ("MUACZ2") was defined as MUACZ $<-2$. Prevalence of acute malnutrition by MUAC ("MUAC125") was defined as $\mathrm{MUAC}<125 \mathrm{~mm}$. Independently for WHZ2 and MUACZ2, outlier observations were excluded from a survey if the Z-score of a child fell outside the flexible exclusion range of $+/-4 \mathrm{Z}$-scores from the observed survey sample mean, as described by WHO [18]. For MUACZ2, observations were excluded if they were less than $70 \mathrm{~mm}$ or greater than $220 \mathrm{~mm}$. To describe the observed prevalences, we computed the medians and interquartile ranges (IQR) of survey level prevalence for each country, region, and overall (Table 1). Prevalences and summary statistics were produced for all children 6-59 months, as well as for two age categories of children, 6-23 months and 24-59 months.

To examine the relationship between calculated prevalences for the three indicators, three analyses were performed. First, for each survey the difference in prevalence was calculated for each of the three indicator pairs (WHZ2 v. MUACZ2, WHZ2 v. MUAC125, and MUACZ2 v. MUAC125). Second, we plotted the correlations of survey level prevalences for each of the three indicator pairs. Both Spearman and Pearson's correlations were calculated. Additionally, multivariable linear regression was modeled with MUACZ2 and MUAC125 prevalence as outcome. For each of the multivariable models, we included the following predictor variables, previously found to be associated with MUAC: WHZ2, stunting prevalence $(H A Z<-2)$, age ratio, and sex ratio of the survey sample. Age ratio was calculated as the proportion of children 6-23 months v. 24-59 months in the sample. All predictor variables were retained in the multivariable model regardless of significance in univariate models [4].

Finally, we examined diagnostic overlap of the indicators. For each of three pairwise comparisons (WHZ2 v. MUACZ2, WHZ2 v. MUAC125, and MUACZ2 v. MUAC125) we performed analysis on the subset of children that were diagnosed as acutely malnourished by 
Table 1 Prevalence of acute malnutrition among children 6-59 months by anthropometric indicator (WHZ, MUACZ and MUAC), by country and region

\begin{tabular}{|c|c|c|c|c|c|c|c|c|}
\hline Region & Country & $\begin{array}{l}\mathrm{N} \\
\text { Surveys }\end{array}$ & $\begin{array}{l}\mathrm{N} \text { children } \\
\text { with WHZ }\end{array}$ & $\begin{array}{l}\text { Median Prevalence } \\
\mathrm{WHZ}<-2 \text { (IQR) }\end{array}$ & $\begin{array}{l}\mathrm{N} \text { children } \\
\text { with MUACZ }\end{array}$ & $\begin{array}{l}\text { Median Prevalence } \\
\text { MUACZ<-2 (IQR) }\end{array}$ & $\begin{array}{l}\mathrm{N} \text { children } \\
\text { with MUAC }\end{array}$ & $\begin{array}{l}\text { Median Prevalence } \\
\text { MUAC }<125 \text { (IQR) }\end{array}$ \\
\hline \multirow{4}{*}{$\begin{array}{l}\text { Latin America \& } \\
\text { Caribbean }\end{array}$} & Bolivia & 1 & 882 & 1.36 & 882 & 0.91 & 882 & 0.57 \\
\hline & Guatemala & 2 & 1,420 & $1.98(0.38-3.58)$ & 1,429 & $7.20(1.33-13.07)$ & 1,430 & $4.52(0.19-8.85)$ \\
\hline & Haiti & 24 & 13,268 & $4.49(3.89-4.86)$ & 13,272 & $6.28(4.17-7.60)$ & 13,306 & $3.16(2.47-3.90)$ \\
\hline & REGION TOTAL & 27 & 15,570 & $4.35(3.76-4.85)$ & 15,583 & $6.25(4.15-8.07)$ & 15,618 & $2.99(2.20-4.10)$ \\
\hline \multirow{4}{*}{$\begin{array}{l}\text { Middle East \& } \\
\text { North Africa }\end{array}$} & Iraq & 1 & 569 & $2.28(2.28-2.28)$ & 568 & $2.64(2.64-2.64)$ & 575 & $3.30(3.30-3.30)$ \\
\hline & Jordan & 5 & 2,089 & $1.23(0.92-1.44)$ & 2,088 & $0.83(0.62-0.96)$ & 2,090 & $0.96(0.41-1.06)$ \\
\hline & Yemen & 3 & 1,199 & $5.52(3.58-16.93)$ & 1,207 & $6.40(2.05-9.66)$ & 1,208 & $4.14(2.38-6.53)$ \\
\hline & REGION TOTAL & 9 & 3,857 & $2.28(1.23-3.58)$ & 3,863 & $1.33(0.83-2.64)$ & 3,873 & $1.23(0.96-3.30)$ \\
\hline \multirow{14}{*}{$\begin{array}{l}\text { West \& Central } \\
\text { Africa }\end{array}$} & Burkina Faso & 11 & 6,387 & $12.79(7.54-16.09)$ & 6,406 & 16.35 (9.18-18.75) & 6,416 & $7.28(3.61-10.32)$ \\
\hline & $\begin{array}{l}\text { Central African } \\
\text { Republic }\end{array}$ & 13 & 8,725 & $5.89(5.56-7.72)$ & 8,677 & 17.49 (14.7-20.76) & 8,693 & $9.22(7.61-9.73)$ \\
\hline & Ivory Coast & 1 & 699 & $4.29(4.29-4.29)$ & 700 & $0.57(0.57-0.57)$ & 700 & $0.14(0.14-0.14)$ \\
\hline & Cameroon & 13 & 6,029 & $8.83(6.90-11.93)$ & 6,046 & $13.15(8.81-14.70)$ & 6,058 & $6.77(4.49-7.62)$ \\
\hline & $\begin{array}{l}\text { Republic of } \\
\text { Congo }\end{array}$ & 58 & 52,545 & $7.88(4.89-11.23)$ & 52,488 & $15.31(10.54-22.52)$ & 52,557 & $7.90(5.50-13.41)$ \\
\hline & Guinea & 5 & 4,034 & $6.44(5.47-7.69)$ & 4,047 & $7.52(3.52-9.48)$ & 4,055 & $4.01(3.16-5.64)$ \\
\hline & Liberia & 6 & 1,961 & $3.41(3.13-4.19)$ & 1,977 & $4.81(2.30-5.60)$ & 1,978 & $2.61(0.92-4.47)$ \\
\hline & Mali & 15 & 10,814 & $11.20(8.70-16.14)$ & 10,868 & $11.04(5.43-15.95)$ & 10,879 & $5.88(2.62-7.65)$ \\
\hline & Mauritania & 6 & 3,671 & $12.68(8.77-14.81)$ & 3,687 & $9.94(7.42-13.21)$ & 3,692 & $5.46(4.45-7.90)$ \\
\hline & Niger & 14 & 9,796 & $12.99(11.40-15.77)$ & 9,772 & $17.36(14.94-24.31)$ & 9,785 & $9.81(7.25-16.18)$ \\
\hline & Nigeria & 2 & 969 & $22.03(16.25-27.81)$ & 976 & $25.03(14.38-35.69)$ & 980 & $18.51(8.71-28.31)$ \\
\hline & Sierra Leone & 6 & 5,417 & $7.12(6.43-7.40)$ & 5,401 & $14.22(11.15-15.78)$ & 5,411 & $9.89(7.67-10.67)$ \\
\hline & Chad & 67 & 38,245 & $9.76(6.34-18.89)$ & 38,233 & $7.62(5.35-19.46)$ & 38,266 & $3.76(2.06-11.89)$ \\
\hline & REGION TOTAL & 217 & 149,292 & $9.46(6.10-13.95)$ & 149,278 & $13.00(7.29-19.65)$ & 149,470 & $6.69(3.67-10.80)$ \\
\hline \multicolumn{2}{|c|}{ Democratic Republic of Congo } & 105 & 91,026 & $8.58(4.97-11.44)$ & 90,983 & $16.70(11.48-22.60)$ & 91,150 & $10.15(6.93-13.85)$ \\
\hline \multirow{14}{*}{$\begin{array}{l}\text { Eastern \& } \\
\text { Southern Africa }\end{array}$} & Angola & 1 & 869 & 5.98 & 866 & 10.85 & 869 & 5.29 \\
\hline & Burundi & 7 & 3,484 & $5.73(4.23-7.08)$ & 3,496 & $7.08(5.90-21.71)$ & 3,499 & $3.03(2.08-9.61)$ \\
\hline & Djibouti & 5 & 1,561 & $10.81(10.36-13.84)$ & 1,578 & $7.96(7.85-11.89)$ & 1,580 & $4.65(3.78-5.75)$ \\
\hline & Eritrea & 2 & 671 & $20.22(18.89-21.55)$ & 674 & $8.63(7.76-9.51)$ & 674 & $4.31(4.02-4.60)$ \\
\hline & Ethiopia & 55 & 26,144 & $16.91(8.71-21.77)$ & 25,961 & $11.29(7.98-17.88)$ & 25,991 & $5.09(3.36-8.50)$ \\
\hline & Kenya & 55 & 34,039 & $11.11(8.05-14.51)$ & 34,148 & $9.62(6.84-12.78)$ & 34,173 & $3.76(2.81-5.28)$ \\
\hline & Madagascar & 8 & 3,695 & $6.39(3.49-7.64)$ & 3,715 & $16.70(11.69-20.74)$ & 3,721 & $7.94(5.48-10.65)$ \\
\hline & Rwanda & 12 & 4,439 & $4.71(3.68-5.84)$ & 4,439 & $4.28(3.43-5.75)$ & 4,441 & $2.28(1.83-3.48)$ \\
\hline & Somalia & 4 & 3,549 & $15.55(14.46-16.14)$ & 3,556 & $20.86(11.27-27.19)$ & 3,558 & 11.27 (3.96-18.21) \\
\hline & South Sudan & 31 & 19,838 & $16.36(9.31-25.16)$ & 19,866 & $16.23(10.26-18.66)$ & 19,898 & 7.95 (5.60-9.52) \\
\hline & Tanzania & 5 & 2,476 & $1.90(1.54-2.61)$ & 2,484 & $5.69(4.03-5.95)$ & 2,485 & $1.18(0.74-3.33)$ \\
\hline & Uganda & 35 & 34,006 & $6.02(3.92-9.43)$ & 34,014 & $12.41(9.51-15.68)$ & 34,068 & $7.60(4.31-10.33)$ \\
\hline & Zimbabwe & 2 & 591 & $4.40(4.38-4.42)$ & 593 & $15.07(3.36-26.78)$ & 596 & $6.38(2.35-10.40)$ \\
\hline & REGION TOTAL & 222 & 135,362 & $10.03(6.20-16.87)$ & 135,390 & $11.10(7.48-16.19)$ & 135,553 & $5.02(3.11-8.24)$ \\
\hline Sudan & & 136 & 117,640 & $18.60(13.61-22.22)$ & 117,471 & $17.52(13.45-21.59)$ & 117,593 & $9.55(6.97-12.54)$ \\
\hline \multirow{3}{*}{$\begin{array}{l}\text { East Asia \& } \\
\text { Pacific }\end{array}$} & Indonesia & 3 & 1,599 & $20.10(17.93-24.58)$ & 1,599 & $22.18(17.87-24.16)$ & 1,599 & $9.24(6.53-10.91)$ \\
\hline & Myanmar & 17 & 11,958 & $18.87(8.49-20.82)$ & 11,973 & $26.84(23.74-30.18)$ & 11,985 & 14.19 (10.58-15.06) \\
\hline & Philippines & 4 & 2,927 & $5.96(4.74-8.67)$ & 2,900 & $2.56(1.93-3.51)$ & 2,898 & $1.26(0.95-1.62)$ \\
\hline
\end{tabular}


Table 1 Prevalence of acute malnutrition among children 6-59 months by anthropometric indicator (WHZ, MUACZ and MUAC), by country and region (Continued)

\begin{tabular}{lllllllll}
\hline Region & Country & N & N children & Median Prevalence & $\begin{array}{l}\text { N children } \\
\text { with MUACZ }\end{array}$ & $\begin{array}{l}\text { Median Prevalence } \\
\text { MUACZ }<-2(\text { (IQR) }\end{array}$ & $\begin{array}{l}\text { N children } \\
\text { with MUAC }\end{array}$ & $\begin{array}{l}\text { Median Prevalence } \\
\text { MUAC< 125 (IQR) }\end{array}$ \\
\hline \multirow{3}{*}{ South Asia } & REGION TOTAL & 24 & 16,484 & $18.09(6.15-20.46)$ & 16,472 & $23.90(13.93-28.20)$ & 16,482 & $11.27(5.00-14.98)$ \\
& Afghanistan & 58 & 46,397 & $7.23(5.50-9.37)$ & 46,268 & $15.08(12.14-23.14)$ & 46,326 & $9.54(6.90-14.26)$ \\
& Bangladesh & 42 & 20,002 & $13.10(11.69-15.54)$ & 20,031 & $13.79(8.96-17.61)$ & 20,061 & $5.91(4.54-7.89)$ \\
& India & 8 & 3,597 & $23.76(18.86-35.41)$ & 3,604 & $27.10(16.65-30.58)$ & 3,604 & $11.19(7.09-13.21)$ \\
& Nepal & 12 & 6,874 & $12.21(6.40-17.91)$ & 6,885 & $19.83(4.64-32.07)$ & 6,889 & $8.87(2.64-16.63)$ \\
& Pakistan & 22 & 16,207 & $17.87(11.83-20.85)$ & 16,228 & $19.26(17.34-29.20)$ & 16,258 & $10.55(8.49-17.07)$ \\
& REGION TOTAL & 142 & 93,077 & $11.69(6.83-15.54)$ & 93,016 & $16.28(11.43-23.14)$ & 93,138 & $8.48(5.60-13.10)$ \\
TOTAL & 882 & 622,308 & $10.57(6.28-16.51)$ & 622,056 & $14.01(8.81-19.95)$ & 622,877 & $7.27(4.39-11.19)$ \\
\hline
\end{tabular}

MUAC Mid-upper arm circumference, MUACZ Mid-upper arm circumference-for-age Z-score, WHZ Weight-for-height Z-Score, IQR Interquartile ranges

both indicators or uniquely by one of the indicators in the pair. For these acutely malnourished children, by survey, the proportions of children in each of three categories were calculated: identified by both indicators in the pair, identified by only one indicator, or identified by only the other indicator. For this analysis, surveys were excluded if the number of acutely malnourished children in the sample was less than 10 children. Survey level analyses of diagnostic overlap are presented graphically.

All data aggregation, cleaning and analyses were performed using SAS version 9.3 [19] and all figures were produced using RStudio version 1.0.15 and the ggplot2 package $[20,21]$.

\section{Results}

A total of 980 surveys conducted between 2001 and 2017 were reviewed. Of these, 39 surveys were excluded due to their design - small sample sizes $(n=20)$ or too few clusters $(n=19)$. Six surveys were excluded due to high proportion of missing values. Additionally, 53 surveys were excluded due to concerns about quality of the WHZ, MUAC or MUACZ measurements $(n=40)$, reported sex $(n=1)$, or within survey duplication $(n=12)$. For only diagnostic overlap, from the 882 final surveys, sixteen were excluded when less than 10 children were identified as malnourished by any criteria.

Of the 882 surveys retained for analysis, 207 surveys were obtained from UNHCR and 675 surveys were from ACF. Overall, 768 surveys used cluster design, 104 used a simple/systematic random sampling design, and 10 were exhaustive samples. Surveys median sample size was 709 children aged 6-59 months (IQR: 503-927). The majority of surveys were conducted in West and Central Africa $(n=217)$, Eastern and Southern Africa ( $n$ $=222)$, South Asia $(n=142)$ and Sudan $(n=136)$. The lowest number of surveys $(n=9)$ were available from the Middle East and North Africa (Table 1).

Table 1 presents the median prevalence of acute malnutrition for each of the three anthropometric indicators. Median prevalence of acute malnutrition overall was highest for MUACZ2 (14.0\%) followed by WHZ2 (10.6\%), and lowest for MUAC125 (7.3\%). This held true in all regions except the Middle East and North Africa, where WHZ2 was higher than MUACZ2 (2.3 and 1.3\%, respectively), and the DRC where MUAC125 was higher than WHZ2 (10.2 and 8.6\%, respectively). Prevalence of WHZ2 was higher than MUAC125 in $70.3 \%$ of surveys and $76.2 \%$ of countries. Prevalence of MUACZ2 was higher than WHZ2 in $65.7 \%$ of surveys and $65.3 \%$ of countries. Prevalence of MUACZ2 was higher than MUAC in all but one survey (Table 1, Fig. 1). Figure 1 presents the difference in prevalence between each pair of indicators by survey, grouped by region, illustrating the range in magnitude of these differences. The comparisons of prevalence (Table 1, Fig. 1) also illustrate that overall, survey prevalence of WHZ2 was only marginally more similar to MUACZ2 than MUAC125, as the absolute difference between median MUACZ2 and WHZ2 (3.4\%) is approximately the same as the absolute difference between median WHZ2 and MUAC125 (3.3\%). The prevalence of WHZ2 was more similar to MUACZ2 than MUAC125 in $51.3 \%$ of surveys and $51.2 \%$ of countries.

Figure 2 presents the correlation between the prevalences for the three indicator pairs for each survey. The correlations of WHZ2 with both MUACZ2 and MUAC125 were weak, positive associations. The correlation between WHZ2 and MUACZ2 was slightly higher (Pearson's $r=0.5757$ ) than correlation between WHZ2 and MUAC125 (Pearson's $r=0.4943$ ). In contrast, the correlation between MUAC125 and MUACZ2 was a strong, linear, positive association (Pearson's $\mathrm{r}=0.9265$ ). No clear regional patterns were observed.

Table 2 presents regression models with prevalence of MUACZ2 and MUAC as outcomes. Unadjusted models included only prevalence of WHZ2 as a predictor. Adjusted models additionally included HAZ2, age and sex ratios of survey samples as predictors. The model for MUACZ2 had 


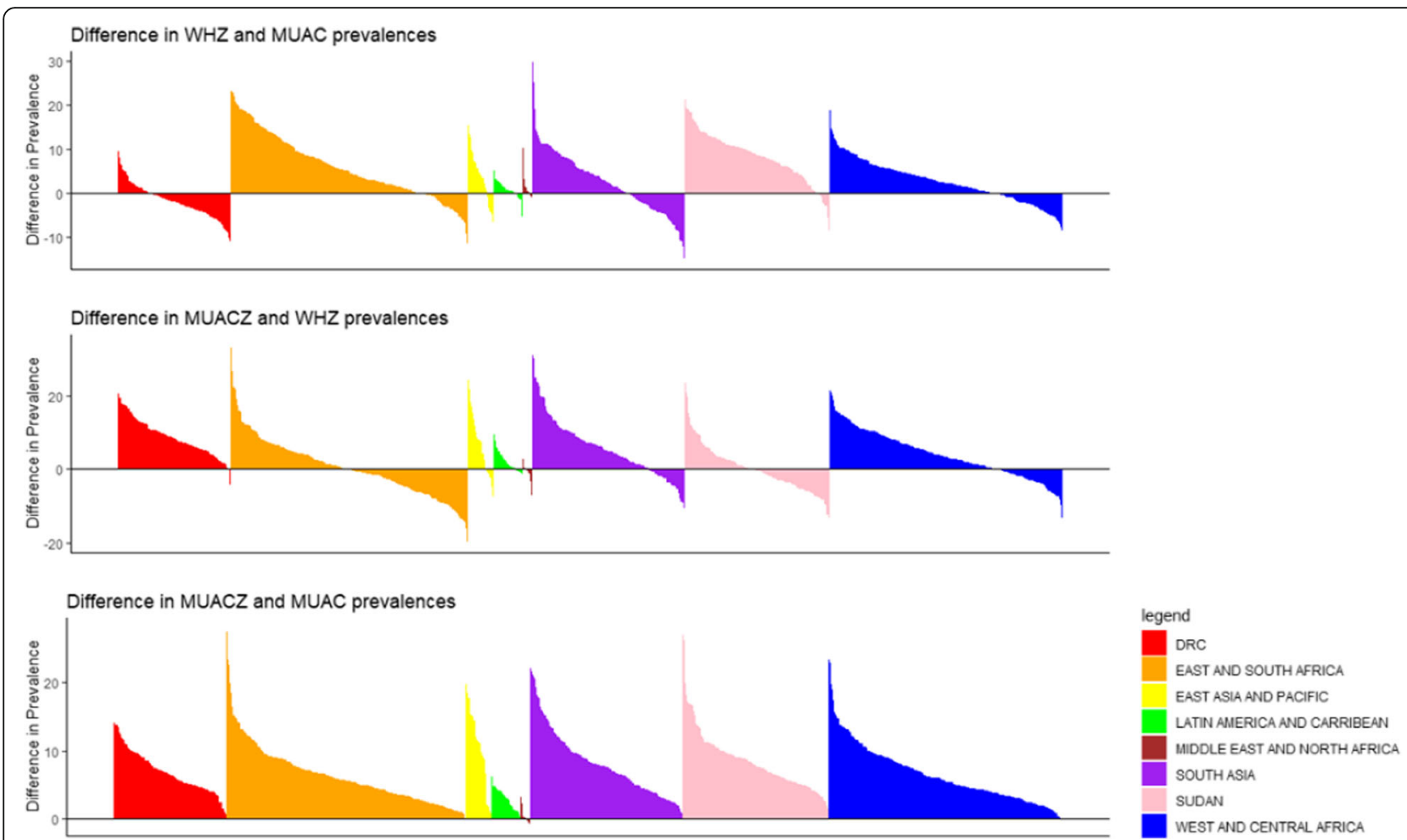

Fig. 1 Survey-level differences in prevalence of acute malnutrition among children 6-59 months by anthropometric indicator pairs (WHZ and MUAC, MUACZ and WHZ, MUACZ and MUAC), by country ( $n=882)$. Legend: Regions represented by colors are as follows: Democratic Republic of Congo (red), East and South Africa (orange), East Asia and Pacific (yellow), Latin America and Caribbean (green), Middle East and North Africa (brown), South Asia (purple), Sudan (pink), West and Central Africa (blue)

higher fit $\left(R^{2}=0.50\right)$ relative to the unadjusted model where only WHZ2 was used as a predictor $\left(R^{2}=0.33\right)$. Similarly, the fit of the unadjusted model of MUAC125 v. WHZ2 improved after controlling for prevalence of stunting, age ratio, and sex ratio of the surveys $\left(R^{2}=0.24\right.$ and $R^{2}=0.43$, respectively). For both adjusted and unadjusted models, $R^{2}$ values were slightly higher for MUACZ2 than MUAC125. Coefficients for WHZ2 in both adjusted models were positive and less than 1.0, MUACZ2 $\left(\beta_{W H Z 2}=0.84\right)$ and MUAC125 $\left(\beta_{W H Z 2}=0.47\right)$. Coefficients of WHZ2 in the unadjusted models were smaller but not meaningfully different than those in the adjusted models $\left[\left(\beta_{W H Z 2}=0.70\right)\right.$ and MUAC125 $\left.\left(\beta_{W H Z 2}=0.36\right)\right]$. Stunting was highly significant in both models $(p$-value $<0.0001)$, with small, positive coefficients $\left(\beta_{\text {HAZ2 }}=0.23\right.$ for MUACZ2 and $\beta_{\text {HAZ2 }}=0.14$ for MUAC125). In the adjusted models, the age ratio of survey sample (6-23 months: $24-59$ months) was not significant $(p$-value $=0.8796)$ in MUACZ2 model but highly significant ( $p$-value $<0.0001$ ) in the MUAC125 model. In the adjusted model for MUAC125, the age ratio variable had a strong, positive association with MUAC125 $\left(\beta_{\text {ageratio }}=7.15\right)$. The sex ratio was insignificant in both models.

Analysis of diagnostic convergence of indicators for diagnosing acute malnutrition in individual children, presented in Table 3, found that overall the median proportion of children identified by both MUAC125 and WHZ2 was $25.5 \%$. By region, the median proportion of children identified by both MUAC125 and WHZ2 was highest in East Asia and Pacific (32.0\%) and lowest in Eastern and Southern Africa (17.7\%). By survey, the proportion of acutely malnourished children diagnosed by both MUAC125 and WHZ2 ranged from 0 to $60.9 \%$ (Fig. 3). The median proportion of children identified by WHZ2 alone (48.2\%) was higher than the median proportion of children identified by MUAC125 alone (21.6\%). This held true across all regions except the DRC (42.1\% MUAC125 only and $27.7 \%$ WHZ2 only).

The overall median proportion of children identified by both MUACZ2 and WHZ2 was slightly higher (30.6\%) than by both MUAC125 and WHZ2. By region, the median proportion of children in a survey identified by both MUACZ2 and WHZ2 was highest in Sudan (38.8\%), and lowest in Latin America and Caribbean (22.9\%). The proportion of acutely malnourished children diagnosed by both MUACZ2 and WHZ2 also varied considerably by survey (range: 0 to $64.2 \%$ ) (Fig. 3). In contrast to the association of MUAC125 and WHZ2, the median proportion of children identified by WHZ2 alone (24.1\%) was smaller than that of MUACZ2 alone (41.4\%). 

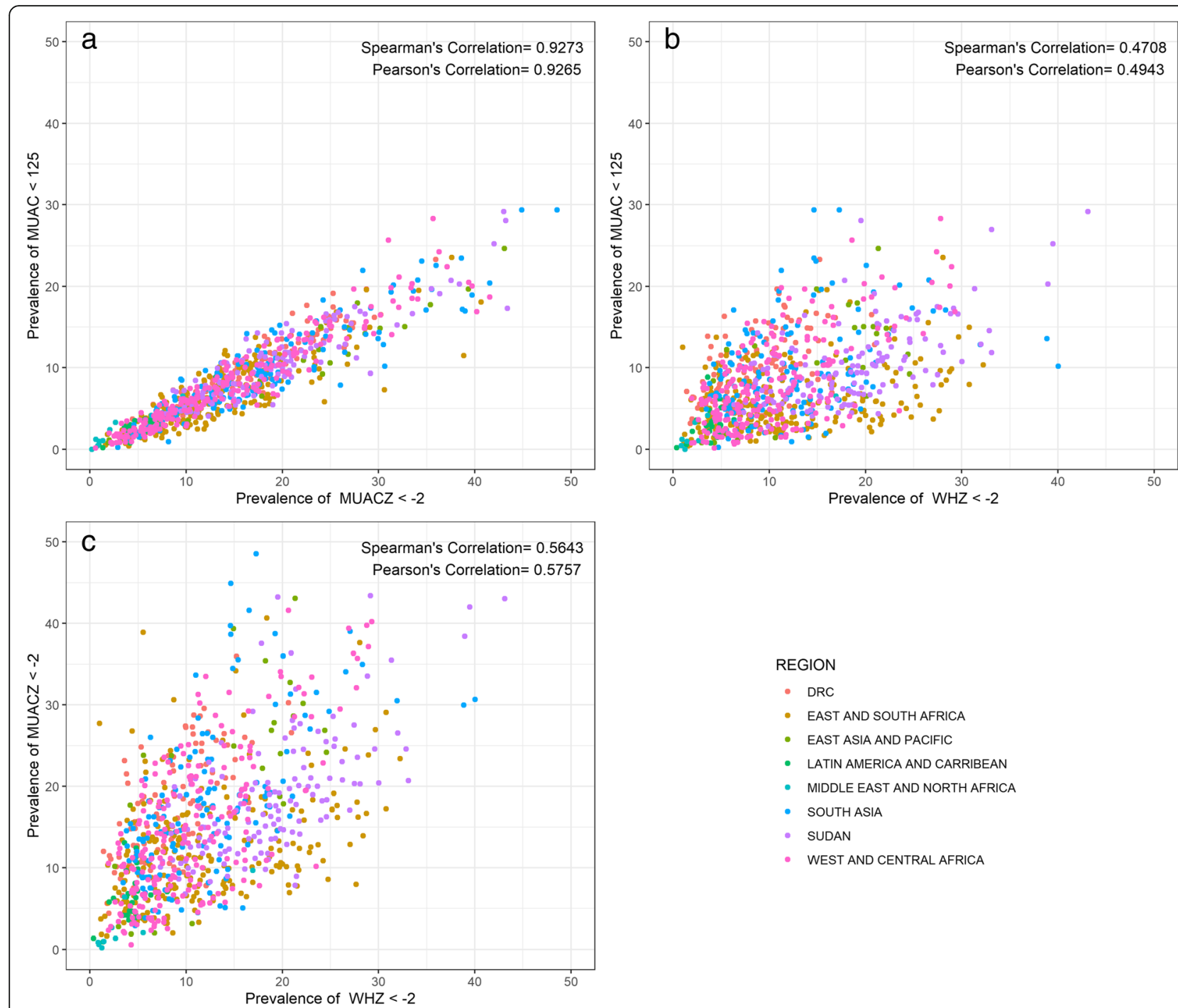

Fig. 2 Pairwise correlation of prevalence of acute malnutrition indictor (MUAC and MUACZ, MUAC and WHZ, WHZ and MUACZ) ( $n=882$ ). Legend: Scatterplots of the correlation color coded by region between a prevalence of MUACZ $<-2$ (x-axis) versus MUAC $<125$ (y-axis), $\mathbf{b}$ prevalence of $\mathrm{WHZ}<-2$ (x-axis) versus $\mathrm{MUAC}<125$ (y-axis), c prevalence of $\mathrm{WHZ}<-2$ (x-axis) and prevalence of MUACZ $<-2$ (y-axis). Regions represented by colors as follows: Democratic Republic of Congo (red), East and South Africa (dark yellow), East Asia and Pacific (green), Latin America and Caribbean (teal), Middle East and North Africa (turquoise), South (blue), Sudan (purple), West and Central Africa (pink)

The median proportion of children identified by both MUAC125 and MUACZ2 in the overall analysis was higher than the diagnostic overlap of WHZ2 with either of those indicators, $40.8 \%$. Median proportion of acutely malnourished children identified by both MUAC125 and MUACZ2 ranged from 35.3\% in Eastern and Southern Africa to $47.1 \%$ in the DRC. The median proportion of children identified by MUACZ2 alone was $51.0 \%$ overall. The proportion of children identified by MUAC125 alone was $7.0 \%$ overall, and below $8.0 \%$ in all regions.

To further explore the finding that age ratio was significantly associated with MUAC125 but not MUACZ2 in multivariable models, median prevalences of all three indicators were stratified by age (6-23 months and 24-59 months), presented in Table 4. For WHZ2, prevalence of acute malnutrition among younger and older children was relatively similar (12.7 and 8.7\%, respectively). The median difference in prevalence of WHZ2 between the two age groups was less than $10 \%$ in all regions. The prevalences of MUACZ2 were very similar for the two age groups, $13.9 \%$ for younger and $13.4 \%$ for older children. In contrast, the median prevalence of acute malnutrition by MUAC125 was more than five times higher for younger children (15.3\%) relative to older children (2.8\%). This difference was most pronounced in Sudan, where there was a difference of $18.6 \%$ between age groups' median prevalences.

Consequently, the pattern of diagnostic overlap of the indicators was different for younger and older children 
Table 2 Multivariable regression models for prevalence of acute malnutrition diagnosed by MUACZ and MUAC

\begin{tabular}{|c|c|c|c|c|}
\hline \multirow{3}{*}{$\begin{array}{l}\text { Survey-level analysis of prevalence } \\
\text { Variable }\end{array}$} & \multicolumn{2}{|l|}{ MUAC for Age } & \multicolumn{2}{|l|}{ MUAC } \\
\hline & \multicolumn{2}{|c|}{ Prevalence MUACZ $<-2$} & \multicolumn{2}{|c|}{ Prevalence MUAC $<125$} \\
\hline & Estimate $(95 \% \mathrm{Cl})$ & $p$-value & Estimate (95\% Cl) & $p$-value \\
\hline Acute malnutrition $(\mathrm{WHZ}<-2)$ prevalence & $0.84(0.78-0.90)$ & $<0.0001$ & $0.47(0.43-0.50)$ & $<0.0001$ \\
\hline Stunting $(H A Z<-2)$ prevalence & $0.23(0.20-0.25)$ & $<0.0001$ & $0.14(0.12-0.15)$ & $<0.0001$ \\
\hline Two-category age ratio (6-23 v. 24-59 months) & $-0.29(-4.11-3.52)$ & 0.8796 & $7.15(4.70-9.60)$ & $<0.0001$ \\
\hline Sex Ratio (Male to Female) & $1.50(-3.28-6.28)$ & 0.5389 & $0.56(-2.51-3.63)$ & 0.7206 \\
\hline Adjusted Model $\mathrm{R}^{2}$ & 0.4968 & & 0.4277 & \\
\hline Acute malnutrition $(\mathrm{WHZ}<-2)$ prevalence & $0.70(0.63-0.76)$ & $<0.0001$ & $0.36(0.32-0.40)$ & $<0.0001$ \\
\hline Unadjusted Model $\mathrm{R}^{2}$ & 0.3314 & & 0.2444 & \\
\hline
\end{tabular}

MUAC Mid-upper arm circumference, MUACZ Mid-upper arm circumference-for-age Z-score, WHZ Weight-for-height Z-Score, HAZ Height-for-age Z-Score

(Table 5). For MUACZ2 and WHZ2, the proportion of children identified by both was similar for younger and older groups $(35.8 \%$ versus $28.0 \%)$. Whereas, for MUAC125 and WHZ2, the proportion of children identified by both was much higher for younger children (34.8\%) than older children (14.0\%). Notably, among older children, the proportion of children identified by both MUACZ2 and WHZ2 was nearly double the proportion identified by both MUAC125 and WHZ2; by contrast, in younger children the proportions were approximately equal $(35.8 \%$ v. $34.8 \%$ respectively). The proportion of children diagnosed by MUAC125 and MUACZ2 were very different in younger and older children (70.5 and 20.0\%, respectively). Among older children, all acutely malnourished children not identified by both indicators were diagnosed only by MUACZ2; MUAC125 had no added diagnostic benefit.

\section{Discussion}

The primary aim of our analysis was to evaluate the finding by Custudio et al. [8] that acute malnutrition prevalence as measured by MUACZ more closely approximated that of WHZ than absolute MUAC. This finding was also previously supported by a study of Bangladeshi children; a cross sectional survey of 27,767 children - which found that cutoffs for MUAC differed according to age groups when looking at acute malnutrition obtained with WHZ2, suggesting MUACZ as an age-adjusted indicator could resolve those differences [12]. Our analysis, the first multicountry analysis to explore this association, demonstrates that the improvement in fit overall is minor and does not hold for all countries or regions. Overall, the difference in median prevalence comparing WHZ2 and MUACZ2 was approximately the same as the difference in median prevalence comparing WHZ2 and MUAC125, about 3\%. WHZ2 was more similar to MUAC125 in half of the surveys and more similar to MUACZ2 in the other half. In the majority of surveys, WHZ2 was greater than MUAC125, and MUACZ2 was greater than WHZ2.
However, there were surveys and countries where the reverse relationships were found. The correlation of MUACZ2 and WHZ2 (Pearson's $r=0.5757$ ) was slightly higher than the correlation of MUAC125 and WHZ2 (Pearson's $r=0.4943$ ), but both indicators were poorly correlated with WHZ. Both associations were somewhat improved after controlling for stunting, sex and age ratios in regression models.

In addition to population level associations, we examined child level diagnostic implication of using MUACZ, MUAC and WHZ. Custudio et al. [8] previously found that the proportion of children identified as acutely malnourished by both WHZ2 and MUACZ2 was higher than the proportion identified with both WHZ2 and MUAC125. Our analysis confirmed this finding; overall, overlap for WHZ2 and MUACZ2 was slightly higher (30\% of malnourished children) than WHZ2 and MUAC125 (25\%). However, the proportion of children identified by each indicator, and thus the relative improvement, varied considerably by region. The proportion of acutely malnourished children identified by WHZ2 as well as MUAC125 was lower than by WHZ2 and MUACZ2 in nearly all regions. However, in Latin America and the Caribbean, the reverse was true; the overlap of WHZ2 was greater for MUAC125 (26.4\%) than MUACZ2 (22.9\%). Our analysis documents considerable variability by survey within regions, and even within countries. Previous research has documented increased mortality risk among children with both WHZ2 and MUAC125 relative to those identified as malnourished by only one indicator; the relative risk of children with both WHZ2 and MUACZ2 has not been investigated [22]. Among malnourished children not identified by both indicators, MUACZ2 diagnosed more children as malnourished than WHZ2. This is a contrast to the relationship between WHZ and MUAC, in which more children have low WHZ but not low MUAC than the reverse. However, these proportions also varied notably by survey, country and region. 


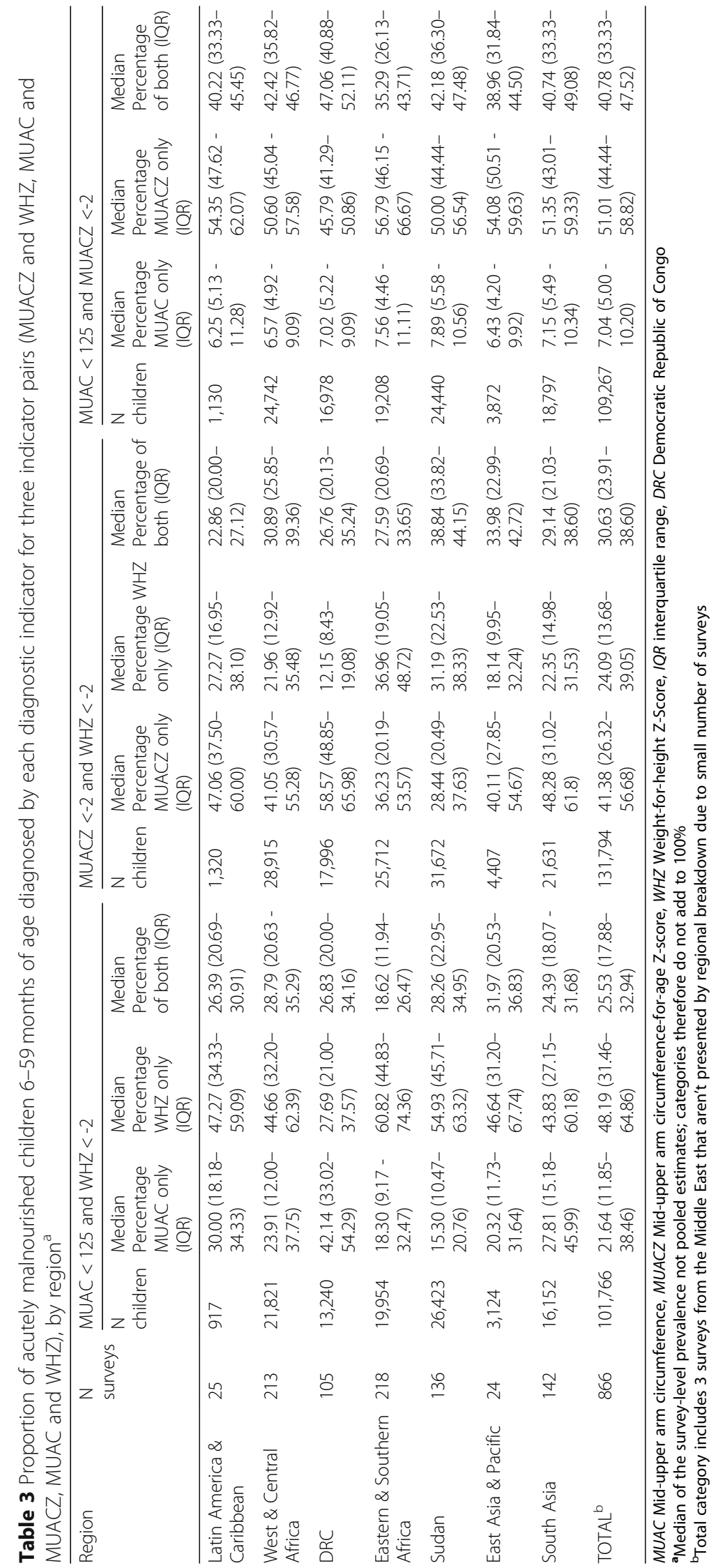




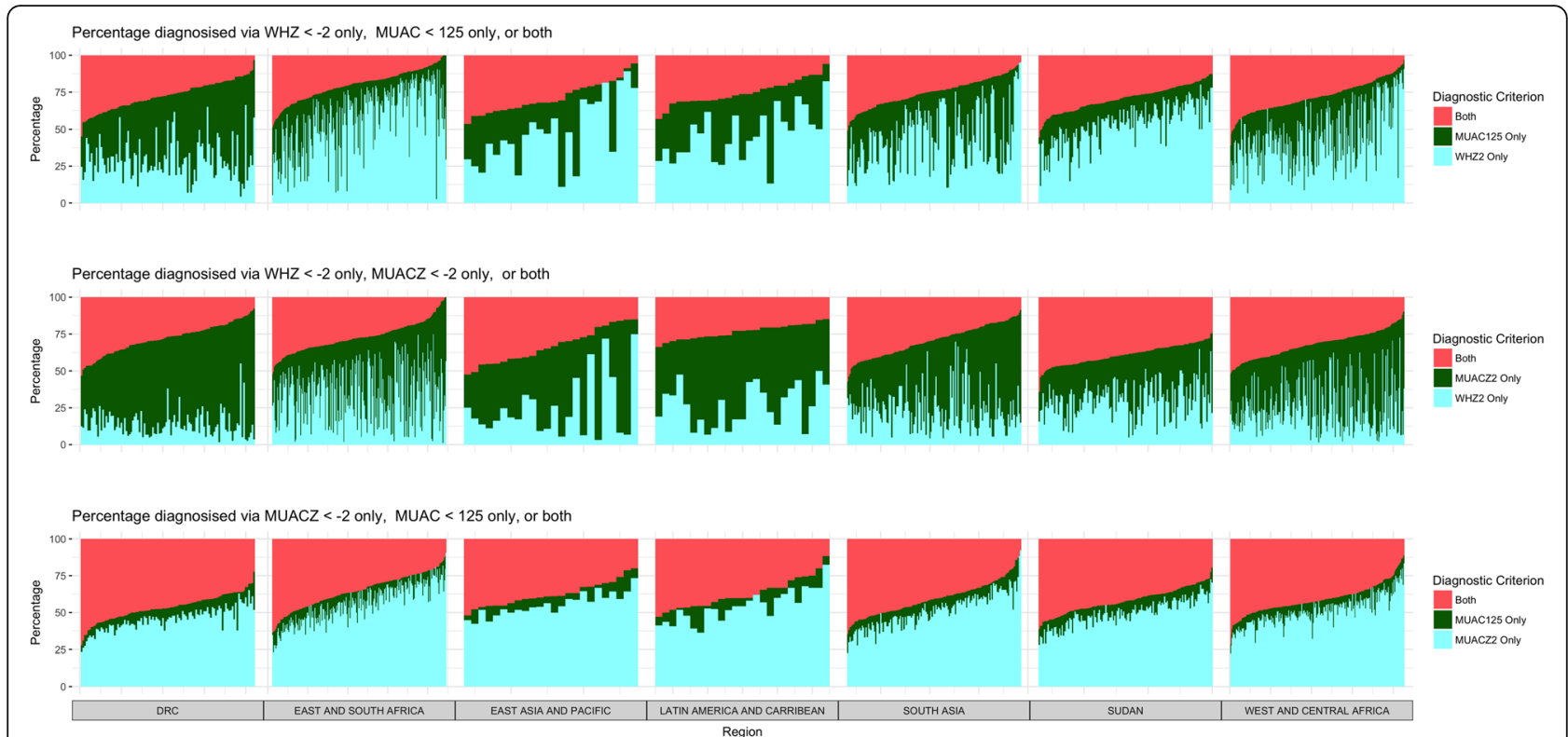

Fig. 3 Contribution of each diagnostic criterion by survey, organized by region, for each of the three indicator combinations (WHZ and MUAC, MUACZ and WHZ, MUACZ and MUAC) ( $n=863)$. Legend: Middle East region excluded given small number of surveys $(n=3)$ included in this analysis. Colors in the top row of graphs represent: both WHZ2 and MUAC125 (pink), MUAC125 only (green), WHZ2 only (blue). Colors in the middle row of graphs represent: both MUACZ2 and WHZ2 (pink), MUACZ2 only (green), WHZ2 only (blue). Colors in the bottom row of graphs represent: both MUAC125 and MUACZ2 (pink), MUAC125 only (green), MUACZ2 only (blue)

Table 4 Prevalences of global acute malnutrition produced by each indicator (WHZ, MUACZ and MUAC) by age group and by region

\begin{tabular}{|c|c|c|c|c|c|c|}
\hline \multirow[t]{2}{*}{ Region } & \multicolumn{2}{|c|}{ Median Prevalence $\mathrm{WHZ}<-2$} & \multicolumn{2}{|c|}{ Median Prevalence MUACZ<-2 } & \multicolumn{2}{|c|}{ Median Prevalence MUAC $<125 \mathrm{~mm}$} \\
\hline & $\begin{array}{l}\text { Age 6-23 months } \\
\text { [N] \% (IQR) }\end{array}$ & $\begin{array}{l}\text { Age 24-59 months } \\
{[\mathrm{N}] \% \text { (IQR) }}\end{array}$ & $\begin{array}{l}\text { Age 6-23 months } \\
{[\mathrm{N}] \% \text { (IQR) }}\end{array}$ & $\begin{array}{l}\text { Age 24-59 months } \\
\text { [N] \% (IQR) }\end{array}$ & $\begin{array}{l}\text { Age 6-23 months } \\
{[\mathrm{N}] \% \text { (IQR) }}\end{array}$ & $\begin{array}{l}\text { Age 24-59 } \\
\text { months } \\
\text { [N] \% (IQR) }\end{array}$ \\
\hline $\begin{array}{l}\text { Latin America \& } \\
\text { Caribbean }\end{array}$ & $\begin{array}{l}{[5,830] 5.65} \\
(4.18-6.96)\end{array}$ & $\begin{array}{l}{[9,740] 3.21} \\
(2.09-3.89)\end{array}$ & $\begin{array}{l}{[5,837] 4.88} \\
(3.76-8.40)\end{array}$ & $\begin{array}{l}{[9,746] 6.29} \\
(3.92-8.93)\end{array}$ & $\begin{array}{l}{[5,852] 5.51} \\
(3.74-8.92)\end{array}$ & $\begin{array}{l}{[9,766] 1.48} \\
(0.77-2.38)\end{array}$ \\
\hline $\begin{array}{l}\text { Middle East \& North } \\
\text { Africa }\end{array}$ & $\begin{array}{l}{[1,400] 2.11} \\
(0.88-4.76)\end{array}$ & $\begin{array}{l}{[2,457] 1.60} \\
(1.11-3.14)\end{array}$ & $\begin{array}{l}{[1,409] 3.45} \\
(0.88-5.70)\end{array}$ & $\begin{array}{l}{[2,454] 0.95} \\
(0.37-1.09)\end{array}$ & $\begin{array}{l}{[1,410] 2.76} \\
(2.63-6.22)\end{array}$ & $\begin{array}{l}{[2,463] 0.47} \\
(0.00-0.94)\end{array}$ \\
\hline West \& Central Africa & $\begin{array}{l}{[53,008] 12.10} \\
(7.79-18.28)\end{array}$ & $\begin{array}{l}{[96,284] 7.42} \\
(4.36-11.44)\end{array}$ & $\begin{array}{l}{[52,882] 12.75} \\
(7.59-19.46)\end{array}$ & $\begin{array}{l}{[96,396] 12.45} \\
(7.00-20.41)\end{array}$ & $\begin{array}{l}{[52,977] 13.96} \\
(7.95-21.27)\end{array}$ & $\begin{array}{l}{[96,493] 2.75} \\
(0.96-5.69)\end{array}$ \\
\hline $\begin{array}{l}\text { Democratic Republic } \\
\text { of Congo }\end{array}$ & $\begin{array}{l}{[34,280] 9.42} \\
(5.76-13.81)\end{array}$ & $\begin{array}{l}{[56,746] 6.81} \\
(4.37-10.30)\end{array}$ & $\begin{array}{l}{[34,232] 15.86} \\
(12.07-21.99)\end{array}$ & $\begin{array}{l}{[56,751] 16.31} \\
(11.78-23.08)\end{array}$ & $\begin{array}{l}{[34,319] 17.84} \\
(13.22-24.08)\end{array}$ & $\begin{array}{l}{[56,831] 5.01} \\
(2.79-7.31)\end{array}$ \\
\hline $\begin{array}{l}\text { Eastern \& Southern } \\
\text { Africa }\end{array}$ & $\begin{array}{l}{[49,039] 10.60} \\
(7.91-16.30)\end{array}$ & $\begin{array}{l}{[86,323] 9.36} \\
(4.76-17.18)\end{array}$ & $\begin{array}{l}{[48,961] 9.77} \\
(5.84-14.71)\end{array}$ & $\begin{array}{l}{[86,429] 11.43} \\
(7.43-16.84)\end{array}$ & $\begin{array}{l}{[49,029] 10.76} \\
(6.31-16.22)\end{array}$ & $\begin{array}{l}{[86,524] 1.76} \\
(0.74-3.40)\end{array}$ \\
\hline Sudan & $\begin{array}{l}{[39,888] 22.84} \\
(16.76-29.68)\end{array}$ & $\begin{array}{l}{[77,752] 16.22} \\
(10.52-19.38)\end{array}$ & $\begin{array}{l}{[39,607] 19.98} \\
(14.26-25.91)\end{array}$ & $\begin{array}{l}{[77,864] 16.44} \\
(12.06-20.68)\end{array}$ & $\begin{array}{l}{[39,685] 21.42} \\
(16.36-29.41)\end{array}$ & $\begin{array}{l}{[77,908] 2.85} \\
(1.80-5.12)\end{array}$ \\
\hline East Asia \& Pacific & $\begin{array}{l}{[5,757] 22.49} \\
(10.58-27.10)\end{array}$ & $\begin{array}{l}{[10,727] 13.83} \\
(4.18-16.72)\end{array}$ & $\begin{array}{l}{[5,728] 20.96} \\
(10.91-26.57)\end{array}$ & $\begin{array}{l}{[10,744] 25.90} \\
(14.14-29.72)\end{array}$ & $\begin{array}{l}{[5,733] 22.08} \\
(9.72-30.67)\end{array}$ & $\begin{array}{l}{[10,749] 4.56} \\
(1.61-6.90)\end{array}$ \\
\hline South Asia & $\begin{array}{l}{[32,422] 14.82} \\
(8.97-21.74)\end{array}$ & $\begin{array}{l}{[60,655] 8.48} \\
(5.15-13.95)\end{array}$ & $\begin{array}{l}{[32,226] 17.49} \\
(11.38-25.26)\end{array}$ & $\begin{array}{l}{[60,790] 15.18} \\
(10.18-21.12)\end{array}$ & $\begin{array}{l}{[32,313] 18.47} \\
(12.55-27.29)\end{array}$ & $\begin{array}{l}{[60,825] 3.06} \\
(1.68-5.19)\end{array}$ \\
\hline TOTAL & $\begin{array}{l}{[221,624] 12.72} \\
(8.17-20.67)\end{array}$ & $\begin{array}{l}{[400,684] 8.73} \\
(4.80-14.74)\end{array}$ & $\begin{array}{l}{[220,882] 13.92} \\
(8.56-20.22)\end{array}$ & $\begin{array}{l}{[40,1174] 13.41} \\
(8.56-20.22)\end{array}$ & $\begin{array}{l}{[221,318] 15.32} \\
(9.17-22.80)\end{array}$ & $\begin{array}{l}{[401,559] 2.75} \\
(1.31-5.01)\end{array}$ \\
\hline
\end{tabular}




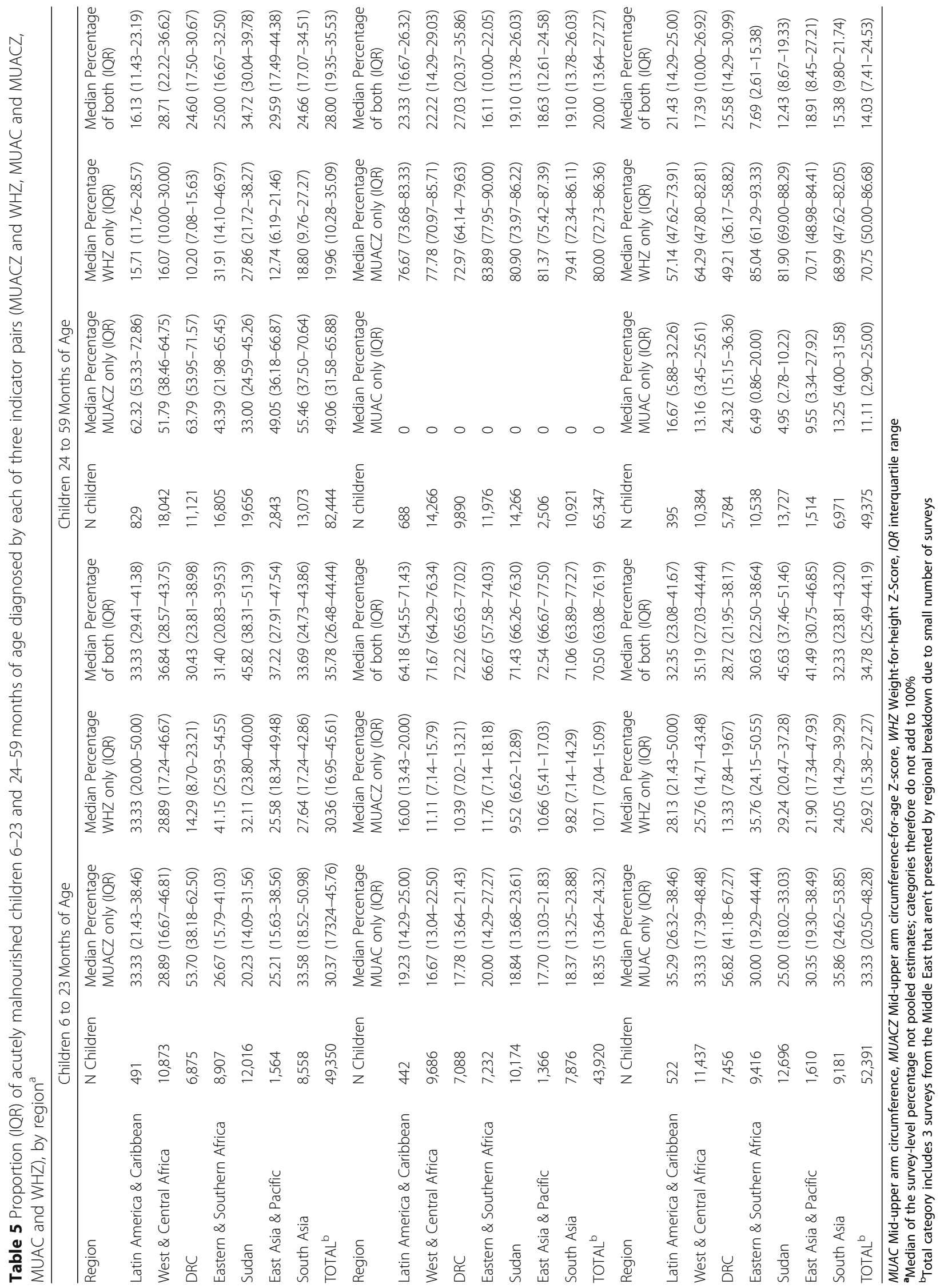


The major factor that distinguishes absolute MUAC and MUACZ is the age-standardization. Consistent with expectations and previous research $[4,11]$, in our multivariable models, age ratio was associated with prevalence of MUAC125 only. The median prevalence of acute malnutrition by MUACZ2 was similar in younger and older children, but five times higher in younger children than in older for MUAC125. Consequently, we were interested in further exploring the impact of age on the association between WHZ and the two MUAC indicators. The proportion of malnourished children identified by WHZ2 as well as MUACZ2 were similar in the younger (6-23 months) and older (24-59 months) age groups (35.8\% v. $28.0 \%$ v, respectively). Whereas, the proportion of malnourished children identified as both WHZ2 and MUAC125 was nearly double for younger children (34.8\% v. $14.0 \%$, respectively). These data suggest a similar relationship between WHZ2 and both MUAC indicators among younger children, but greater discordance for MUAC125 than MUACZ2 for older children.

Since the development and publication of the MUACfor-age reference data in 1997 [11], there has been limited research exploring the association between MUAC and MUACZ. We know of only one small study in Nigeria that directly calculated the diagnostic overlap of the two indicators and found that $35.3 \%$ of acutely malnourished children 6-59 months measured were diagnosed by both MUACZ2 and MUAC125; 17.7\% were MUACZ2 only and $47.0 \%$ were MUAC125 only [23]. Notably, the sample had a disproportionately large number of younger children, $60.8 \%$ of the children were $6-$ 23 months of age. In contrast, our study found that overall, MUACZ2 identified more children than MUAC125. The median prevalence of MUACZ2 in nearly all surveys was notably higher than MUAC125; this finding was very consistent across regions. Unlike the weak association between WHZ2 and both MUAC indicators, the correlation between MUACZ2 and MUAC125 was high $\left(\mathrm{R}^{2} \approx 0.85\right)$. Consequently, it may be possible to devise a relatively reliable formula for conversion of MUAC125 into MUACZ2 prevalence, as was done previously for converting estimates from National Center for Health Statistics (NCHS) growth reference to estimates using the WHO growth standards where a high degree of fit $\left(R^{2}>0.9\right)$ was observed [24].

Interestingly, while the association between MUACZ2 and MUAC125 was strong, only $40 \%$ of children were identified by both indicators. The proportion of children identified by both is very age dependent. Both MUAC125 and MUACZ2 identified similar children in the younger age group (70\% overlap). However, in the older age group, only $20 \%$ of malnourished children were identified by both indicators. The finding that MUAC125 identified no children aged 24 months or older not otherwise identified by MUACZ2, conforms with expectations but has not been described previously in the research. The programmatic implications of this require more research. Data on the prognostic ability of MUACZ2 to predict mortality, especially in older age group, is limited. A study in Guinea-Bissau found no significant difference comparing MUAC125 and MUACZ2 in ability to predict mortality at 30 and at 90 days among children aged 6-35 months [25]. Studies including a broader age group, a longer follow-up period, and multicountry comparisons are not available. Recent study developing and testing MUAC for age growth reference for children aged 5-17 years suggested that MUAC for age is at least as effective as body mass index for age for assessing mortality risks among African school aged children [26].

This study is subject to several limitations. First, analysis is limited to sub-national surveys conducted primarily in emergency settings that were made available for review. These subnational surveys are conducted more frequently in countries with poor nutritional status and ongoing nutritional programming. Consequently, few surveys from Latin American countries and no European countries were available for analysis. In addition, large multi-indicator national surveys, such as Demographic and Health Surveys, measure WHZ but not MUAC or MUACZ. While the final dataset included surveys from 41 countries, the geographic distribution may impact generalizability of findings. Additionally, the surveys included in our study were designed to achieve reasonable precision for global acute malnutrition. The number of children with severe acute malnutrition within these samples was consequently quite small. Therefore, future analysis looking at the association of severe rather than total acute malnutrition by WHZ, MUAC and MUACZ, would require surveys with larger samples or a pooled analysis design. Finally, analysis of age differences requires accurate age estimation. Settings with high acute malnutrition also tend to have poor vital registration. Age is consequently estimated to the nearest month for many of the children (where exact date of birth is not available). Imperfect age estimation may impact the associations described.

\section{Conclusions}

The presented analysis demonstrates some limited improvement in convergence with WHZ when using MUACZ instead of MUAC. Wider use of MUACZ for programming, however, cannot be justified based on these limited improvements. In terms of field logistics, MUAC is more convenient and quick to measure, as MUACZ additionally requires age estimation and use of field-reference tables. Additionally, limited research exists on whether children with low MUACZ have an 
increased risk of mortality, as has been previously documented for low MUAC and low WHZ. Finally, use of MUACZ for admission to treatment should be informed by research on responsiveness of children with low MUACZ, but not low MUAC or low WHZ, to nutrition treatment.

\section{Abbreviations \\ ACF: Action Contre le Faim; DRC: Democratic Republic of Congo; GAM: Global acute malnutrition; HAZ: Height-for-age; IQR: Interquartile ranges; MUAC: Mid-upper arm circumference; MUAC125: MUAC < $125 \mathrm{~mm}$; MUACZ: MUAC-for-age; MUACZ2: MUACZ < - 2; SAM: Severe acute malnutrition; SCN: Standing Committee on Nutrition; SD: Standard deviations; UNHCR: United Nations High Commissioner for Refugees; WHO: World Health Organization; WHZ: Weight-for-height z-score; WHZ2: $W H Z<-2$}

\section{Acknowledgements}

Action Contre la Faim (ACF); United Nations High Commissioner for Human Rights (UNHCR).

\section{Authors' contributions}

EL, OB designed the study. EH, AC analyzed the data and produced tables/ figures. EL, AC drafted the manuscript. EL, AC, EH, OB critically revised the manuscript for important intellectual content. EL, AC, EH, OB read and approved the final manuscript. All authors have read and approved the manuscript, have full access to all of the data, and take responsibility for the integrity of the data and the accuracy of the data analysis.

\section{Funding}

No additional funds were provided for the study.

\section{Availability of data and materials}

The data that support the findings of this study are available from Action Contre la Faim and the United Nations High Commissioner for Human Rights but restrictions apply to the availability of these data, which were used under license for the current study, and so are not publicly available. Data are however available from the authors upon reasonable request and with permission of Action Contre la Faim and the United Nations High Commissioner for Human Rights.

\section{Ethics approval and consent to participate}

Not applicable. Analysis based on secondary analysis of anonymized data where no individual data could be identified so formal ethical clearance was not required. Permission to use the data were obtained from the organizations collecting the datasets.

The findings and conclusions in this report are those of the authors and do not necessarily represent the official position of the Centers for Disease Control. UNHCR data is part of the Public Health Dataset. UNHCR does not warrant in any way the accuracy of the data or information reproduced from the provided Public Health Dataset and may not be held liable for any loss caused by reliance on the accuracy or reliability thereof.

\section{Consent for publication}

Not applicable.

\section{Competing interests}

All authors declare that they have no competing interests; no support from any organization for the submitted work; no financial relationships with any organizations that might have an interest in the submitted work in the previous 3 years; no other relationships or activities that could appear to have influenced the submitted work.

\section{Received: 8 October 2018 Accepted: 11 July 2019}

\section{Published online: 19 August 2019}

\section{References}

1. World Health Organization, World Food Programme, United Nations System Standing Committee on Nutrition \& United Nations Children's Fund (UNICEF). Community-based management of severe acute malnutrition: a joint statement by the World Health Organization, the World Food Programme, the United Nations System Standing Committee on Nutrition and the United Nations Children's Fund. Geneva/New York/Rome: World Health Organization; 2007. https://apps.who.int/iris/handle/10665/44295.

2. World Health Organization, United Nations Children's Fund, Standing Committee on Nutrition. Informal consultation on community-based management of severe malnutrition in children. Geneva: SCN Nutrition Policy; 2006

3. World Health Organization, United Nations Children's Fund. WHO child growth standards and the identification of severe acute malnutrition in infants and children. Geneva: A Joint Statement; 2009.

4. Roberfroid D, Hammami N, Lachat C, Prinzo ZW, Sibson V, Guesdon B, et al. Utilization of a Mid-Upper Arm Circumference Versus Weight-for-Height in Nutritional Rehabilitation Programmes: A Systematic Review of Evidence. Geneva: World Health Organization; 2013. Available at https:/www.who.int/ nutrition/publications/guidelines/updates_management_SAM_ infantandchildren_review1.pdf?ua=1. Accessed 18 July 2019.

5. Grellety EG, Golden MH. Weight-for-height and mid-upper-arm circumference should be used independently to diagnose acute malnutrition: policy implications. BCM Nutr. 2016;2:10.

6. Jelliffe DB, Jelliffe EFP. The arm circumference as a public health index of protein-calorie malnutrition of early childhood. J Trop Pediatr 1967. 1969; 15(4):177-260.

7. Bilukha O, Leidman E. Concordance between the estimates of wasting measured by weight-for-height and by mid-upper arm circumference for classification of severity of nutrition crisis: analysis of populationrepresentative surveys from humanitarian settings. BMC Nutr. 2018;4:24.

8. Custodio E, Martin-Canavate R, Di Marcantanio F, Molla D, Abukar Y, Kayitakire F. MUAC-for age more useful than absolute MUAC for nutritional surveillance in Somalia: results from nineteen cross-sectional surveys (20072016). BCM Nutr. 2018;:4:8.

9. Myatt M, Khara T, Collins S. A review of methods to detect cases of severely malnourished children in the community for their admission into community-based therapeutic care programs. Food Nutr Bull. 2006;27(3 Suppl):S7-23.

10. World Health Organization. Child growth standards: Arm circumference-forage. Available at: http://www.who.int/childgrowth/standards/ac_for_age/ en/. Accessed July 302018.

11. de Onis M, Yip R, Mei Z. The development of MUAC for-age reference data recommended by a WHO expert committee. Bull World Health Organ. 1997; 75:11-8.

12. Houssain Ml, Ahmed T, Arifeen SE, Bilah SM, Faruque A, Islam MM, Jackson AA. Comparison of mid upper arm circumference and weight-for-height $z$ score for assessing acute malnutrition in Bangladeshi children aged 6-60 mo: an analytical study. Am J Clin Nutr. 2017;106(5):1232-7.

13. Standardized Monitoring and Assessment of Relief and Transitions (SMART). Sampling methods and sample size calculation for the SMART methodology. 2012. Available at: http://smartmethodology.org/surveyplanning-tools/smart-methodology/. Accessed 24 July 2018.

14. Proos LA, Hofvander $Y$, Wennqvist $K$, Tuvemo T. A longitudinal study on anthropometric and clinical development of Indian children adopted in Sweden. II. Growth, morbidity, and development during two years after arrival in Sweden. Ups J Med Sci. 1992;97(1):93-106.

15. Grellety E, Golden MH. The effect of random error on diagnostic accuracy illustrated with the anthropometric diagnosis of Malnutrution. PLoS One. 2016;11(12):e0168585.

16. UNICEF. Regional Classifications. UNICEF Data: Monitory the situation of children and women. 2017. Available at: https://data.unicef.org/ regionalclassifications/. Accessed 24 July 2018.

17. WHO Multicentre Growth Reference Group. Child growth standards: length/ height-for-age, weight-for age, weight-for-length and body mass index-forage:methods and development. Geneva: World Health Organization; 2006.

18. World Health Organization, Physical Status: The Use and Interpretation of Anthropometry. Report of the WHO Expert Committee. World Health Organization Technical Report Series, Vol. 854. Geneva: World Health Organization; 1995.

19. Rogerson PA. Statistical methods for geography. London: Sage; 2001.

20. RStudio Team. RStudio: Integrated Development for R. Boston: RStudio, Inc: 2015. Available at: https://www.rstudtio.com/. Accessed 18 July 2019.

21. Wickham H. ggplot2: Elegant Graphics for Data Analysis. New York: Springer-Verlag; 2016. 
22. Grellety E, Golden MH. Severly malnourished children with a low weightfor-height have a highermortality than those with a low mid-upper-armcircumference: I. Emperical data demonstrates Simpson's paradox. Nutr J. 2018;17:79.

23. John C, Ocheke IE, Diala U, Adah RO, Envuladu EA. Does mid upper arm circumference identify all acute malnourished 6-59 month old children, in field and clinical settings in Nigeria? S Afr J Clin Nutr. 2017;30(3):55-9.

24. Yang $\mathrm{H}$, de Onis $\mathrm{M}$. Algorithms for converting estimates of child malnutrition based on the NCHS reference into estimates based on the WHO child growth standards. BMC Pediatr. 2008;8:19.

25. Rasmussen J, Andersen A, Fisker AB, Ravn H, Sodemann M, Rodrigues A, Benn CS, Aaby P. Mid-upper-arm-circumference and mid-upper-arm circumerference z-score: the best predictor of mortality? Eur J Clin Nutr. 2012;66(9):998-1003.

26. Mrambe L, Ngari M, Mwangome M, Muchai L, Bauni E, Walker AS, Gibb DM, Fegan G, Berkley JA. A growth reference for mid upper arm circumference for age among school age children and adolescents, and validation for mortality: growth curve construction and longitudinal cohort study. BMJ. 2017;358:3423.

\section{Publisher's Note}

Springer Nature remains neutral with regard to jurisdictional claims in published maps and institutional affiliations.

Ready to submit your research? Choose BMC and benefit from:

- fast, convenient online submission

- thorough peer review by experienced researchers in your field

- rapid publication on acceptance

- support for research data, including large and complex data types

- gold Open Access which fosters wider collaboration and increased citations

- maximum visibility for your research: over $100 \mathrm{M}$ website views per year

At $\mathrm{BMC}$, research is always in progress.

Learn more biomedcentral.com/submissions 